\title{
SEA-POL GOES TO SEA
}

Steven A. Rutledge, V. Chandrasekar, Brody Fuchs, Jim George, Francesc Junyent, Brenda Dolan, Patrick C. Kennedy, and Kyla Drushka

\author{
A new Sea-Going Polarimetric (SEA-POL) radar was successfully deployed on its inaugural \\ cruise as part of the SPURS-2 project, marking the first shipboard deployment of a \\ polarimetric C-band weather radar by the U.S. research community.
}

0 ver the past several decades, ship-based Doppler radars have been used to probe tropical precipitation systems ranging from large mesoscale convective systems (MCSs) to weakly precipitating stratocumulus clouds. The first shipborne radars were deployed in GARP Atlantic Tropical Experiment (GATE) in 1974. In GATE, four ships were outfitted with $5 \mathrm{~cm}$ wavelength (C band) reflectivity-only radars to examine the structure of tropical MCSs. A wealth of new findings regarding squall lines and accompanying stratiform precipitation emerged from GATE (Houze 1977; Houze and Cheng 1977; Zipser 1977), even though antenna scanning was not stabilized for ship motions and no Doppler velocity data were available. The Equatorial Mesoscale Experiment

AfFiliations: Rutledge, Fuchs, Dolan, and KennedyDepartment of Atmospheric Science, Colorado State University, Fort Collins, Colorado; Chandrasekar, George, AND JunyentDepartment of Electrical and Computer Engineering, Colorado State University, Fort Collins, Colorado; DrUSHKA-Applied Physics Laboratory, University of Washington, Seattle, Washington CORRESPONDING AUTHOR: Prof. Steven A. Rutledge, rutledge@atmos.colostate.edu

The abstract for this article can be found in this issue, following the table of contents.

DOI:10.II75/BAMS-D-18-0233.I

In final form 17 June 2019

(C2019 American Meteorological Society

For information regarding reuse of this content and general copyright information, consult the AMS Copyright Policy.
(EMEX) in 1987 also deployed a ship-based C-band Doppler radar (Webster and Houze 1991), and like during GATE, the radar [Massachusetts Institute of Technology (MIT) C band] was not stabilized for ship motions. The first deployment of ship-based, stabilized Doppler radars was done 5 years later in the Tropical Ocean and Global Atmosphere Coupled Ocean-Atmosphere Response Experiment (TOGA COARE) in 1992, utilizing two Doppler radars, the MIT C band deployed on a U.S. research ship and the NOAA TOGA C-band radar (now known as the NASA-TOGA radar) deployed on a research ship from China. The TOGA COARE ship radars provided new information about rainfall and convection over the western Pacific warm pool (Rickenbach and Rutledge 1998; DeMott and Rutledge 1998). In fact, TOGA COARE also marked the first ship-based dual-Doppler observations, as the two ships carrying these radars approached within $40 \mathrm{~km}$ of one another for approximately one-half day to carry out dual-Doppler observations of oceanic convection (Petersen et al. 1999). Following TOGA COARE, many field projects benefitted from the use of shipbased Doppler radars including the Tropical Eastern Pacific Process Study 1997 (TEPPS; Yuter and Houze 2000), South China Sea Mesoscale Experiment 1998 (SCSMEX; Johnson et al. 2005), Kwajalein Experiment 1999 (KWAJEX; Yuter et al. 2005), Joint Air-Sea Monsoon Interaction Experiment 1999 (JASMINE; Webster et al. 2002), east Pacific Investigation of Climate Processes in the Coupled Ocean- 
Atmosphere System 2001 (EPIC; Petersen et al. 2003), VAMOS Ocean-Cloud-Atmosphere-Land Study 2007 (VOCALS; Wood et al. 2011), and Dynamics of the Madden-Julian Oscillation 2011 (DYNAMO; $\mathrm{Xu}$ and Rutledge 2014, 2015). These projects, with the exception of SCSMEX and DYNAMO, used the C-band Doppler radar on the R/V Ronald H. Brown $(R H B)$, which became a workhorse for ship-based Doppler deployments over this period of time. SCSMEX and DYNAMO used the NASA TOGA C-band Doppler radar. In 2013, NOAA decided to remove the C-band radar from the $R H B$ and donate the radar to Colorado State University (CSU) with the understanding it would be "resurrected" and utilized again aboard ships for research and education purposes. In August 2015, CSU was awarded a Major Research Instrumentation grant from the National Science Foundation (NSF), which funded the design and development of the Sea-Going Polarimetric (SEA-POL) C-band Doppler, dual-polarization radar. SEA-POL was specifically built to ensure easy and economical deployment on multiple ships within the University-National Oceanographic Laboratory System (UNOLS) global class fleet including the $\mathrm{R} / \mathrm{V}$ Roger Revelle, R/V Thomas G. Thompson, and $\mathrm{R} / \mathrm{V}$ Atlantis. SEA-POL can also be deployed on the newer, slightly smaller U.S research ships including the R/V Sally Ride and the R/V Neil Armstrong. Indeed, SEA-POL can also be deployed on the RHB.

The ship-based radar deployments discussed earlier all used single-polarization, C-band radars. There is reasoning for this particular choice of wavelength. The use of $S$ band $(10 \mathrm{~cm}$ wavelength) on ships is precluded since the antenna size $(8.5 \mathrm{~m}$ diameter for a $1^{\circ}$ beamwidth) is prohibitively large. Range is limited on X-band systems, and attenuation can be substantial and, in some cases, difficult to correct for at X-band. The benefits offered by dualpolarization versus single-polarization radars are well established (Bringi and Chandrasekar 2001) and include improved rain-rate estimation, hydrometeor identification, improved data quality through the identification of artifacts and spurious data (including sea clutter), and improved attenuation correction using differential phase. In fact, previous studies have demonstrated that hydrometeor identification algorithms at $\mathrm{C}$ band can provide robust insights into bulk microphysical properties within precipitation echoes (e.g., Dolan et al. 2013; Thompson et al. 2014). There are additional advantages in the choice of $\mathrm{C}$ band for polarimetric observations, including increased specific differential phase $\left(K_{\mathrm{DP}}\right)$ sensitivity to liquid water content compared to $S$ band (Bringi and
Chandrasekar 2001). Enhanced resonance effects due to the presence of large, oblate drops is common at $\mathrm{C}$ band, which provides an excellent marker for melting ice particles and areas of collision-coalescence revealed by large differential reflectivities ranging up to $7 \mathrm{~dB}$ (Carey and Petersen 2015).

This study reports on the design, construction, and capabilities of SEA-POL and its first deployment during the Salinity Processes in the Upper Ocean Regional Study, second field phase (SPURS-2) project, carried out in late fall 2017 on board the R/V Roger Revelle. The SPURS-2 targeted convective systems and rainfall in the east Pacific intertropical convergence zone (ITCZ). We first describe the development of SEA-POL and installation and operation on the $\mathrm{R} / \mathrm{V}$ Roger Revelle. Highlights from the cruise are then presented including polarimetric-based rain maps used to identify freshwater "puddles" on the ocean's surface, which were of particular interest to the SPURS-2 oceanographers. SEA-POL also documented the dynamical and inferred microphysical structure of shallow and deep convection, and stratiform precipitation. Selected results are presented, revealing insights regarding the physics of tropical precipitation.

\section{DESIGN, CONSTRUCTION, AND SHIP INSTALLATION OF SEA-POL. The design and} construction of SEA-POL focused on building a radar that would be rugged from mechanical and electrical perspectives, since the radar deploys on board ships that operate in harsh marine environments. Two components from the $R H B$ radar were used in the construction of SEA-POL, the C-band magnetron transmitter and the antenna positioner (or pedestal, which was completely rebuilt down to the last nut and bolt). All other components were either supplied by a commercial vendor or designed and built in-house at CSU. As stated earlier, the $5.65 \mathrm{GHz}$ (C band) operating frequency is optimal for ship-based operations, since the physical size of the antenna, radome and pedestal assembly is small enough to permit rapid deployment and installation on the host ship, while still providing high spatial resolution and excellent range (Bringi and Chandrasekar 2001). Magnetron transmitters are robust, efficient devices that, when coupled with a coherent-on-receive digital signal processor, provides for high-quality data. The radio frequency $(\mathrm{RF})$ environment aboard a research ship can be difficult for C-band radar operations due to interference from other shipboard equipment. Particular attention to out-of-band rejection in the receiver was used to filter out unwanted RF energy. 
The radar is designed to accept prime power sources available on land $(208 \mathrm{~V})$ and sea $(480 \mathrm{~V})$.

An illustration of SEA-POL is shown in Fig. 1. The radar shelter uses a standard-sized seatainer, which houses the radar transmitter, signal processor, data recording system, and computers and displays for monitoring SEA-POL data in real time. During SPURS-2, we established remote operation and monitoring of the radar in the computer laboratory of the ship. Working in the computer laboratory allowed staff to avoid walking to and from the radar during rough seas and/or foul weather, which can pose safety hazards. Engineering staff typically visited the radar seatainer once or twice per day to ensure smooth operations. The remote displays also included a camera inside the radome, allowing antenna motions to be monitored. The seatainer is cooled using a marinerated air conditioning system. A radome dehydrator system is used to prevent condensation inside the radome, including the antenna and radar receiver electronics.

The radar shelter (seatainer) is a modified 20 foot ISO shipping container, which permits ease of handling by dockside equipment such as cranes as well as facilitating road and ship transportation of the radar to remote locations. The radar platform is a custom design and fabrication allowing the antenna, radome and pedestal to rigorously mount to the top of the radar shelter. It has the same footprint as a container, and uses ISO-standard corner cube castings to allow it to be treated like a platform container, so it ships just like a seatainer, by truck or container ship. The circular collar at the top of the radar platform breaks into three components for shipping. The entire radar is shipped in three standard sized seatainers that includes the radar shelter and two custom-built seatainers that house the disassembled radome, antenna, pedestal, spare parts, test equipment, tools, and safety gear. Adequate space for other equipment and supplies is also available.

SEA-POL uses a $4.3 \mathrm{~m}$ diameter reflector antenna. The reflector assembly is made of fiberglass to make it lightweight and easy to handle for dockside assembly and disassembly. The antenna uses a dual-linear polarization feed horn to generate a pencil beam of $1^{\circ}$ beamwidth. The antenna has outstanding sidelobe suppression, greatly reducing sea clutter. The reflector breaks down into five pieces to fit within the $2.5 \mathrm{~m}$ maximum allowed width inside a seatainer. The spars holding the feed horn are equipped with precision locating pins to allow repeatable performance between successive installations of the radar. The two-axis antenna positioner (pedestal) allows

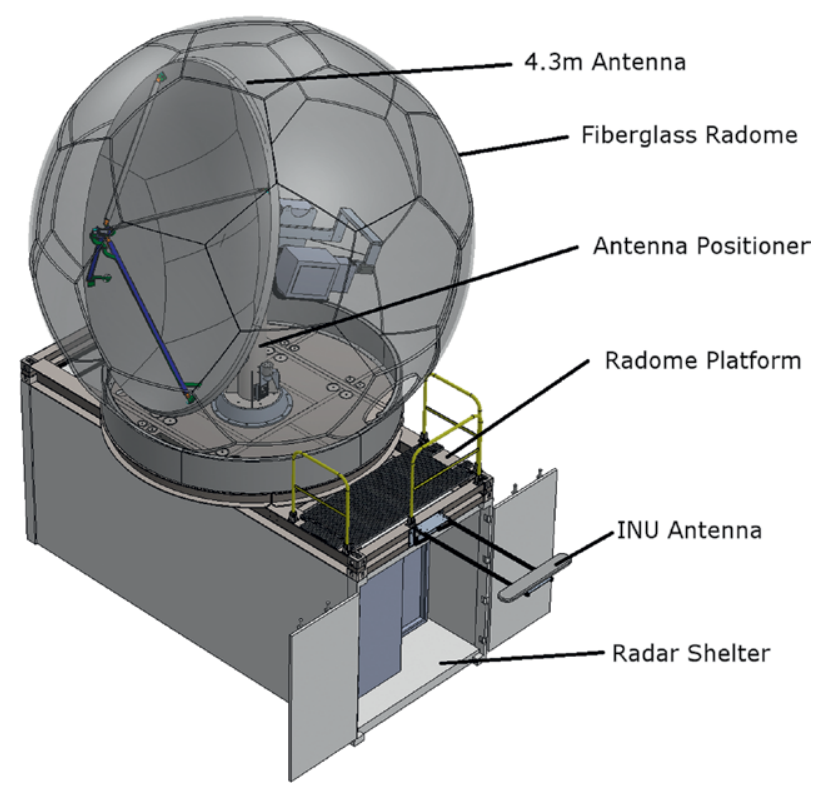

FIG. I. Schematic of the SEA-POL radar as viewed from above. The radar shelter is a standard sized seatainer. The radome encloses the antenna, positioner, and radar receiver. Although not shown, a custom hatch provides access to the interior of the radome while at sea. [This figure is reprinted from Rutledge et al. (2019) under the terms of the Creative Commons Attribution 4.0 International License (https://creativecommons.org /licenses/by/4.0/).]

positioning of the antenna in azimuth and elevation. Elevation travel is from $-5^{\circ}$ to $+85^{\circ}$, with continuous rotation in azimuth. Waveguide rotary joints allow the transmitter pulse to traverse the rotation axes. The azimuth rotary joint also includes a fiber-optic channel and slip rings for radar data and control signals. Servo amplifiers accept commands from the radar controller to move the antenna at speeds up to $30^{\circ} \mathrm{s}^{-1}$. The drives are tuned for high accelerations and quick response time, which permits the dynamic repositioning required for antenna stabilization at sea.

An inertial navigation unit (INU; mounted on the antenna positioner) measures both the static and dynamic pitch and roll of the radar antenna platform at a frequency of $60 \mathrm{~Hz}$. Static heading is also measured. This information is used to offset the scanning plane of the radar (due to roll and pitch movements by the ship) by adjusting the elevation axis on a continuous basis during plan position indicator (PPI) and range-height indicator (RHI) scans. The measured heading information is used to correct the azimuth angles so that the radar always makes measurements in Earth-centric coordinates. In addition to the coordinate transformation between the two coordinate systems, the roll and pitch rates are used to 
compute a dynamic elevation angle adjustment such that the error between commanded and actual Earthrelative elevation angle is constantly minimized. The antenna and positioner are enclosed within a fiberglass radome that has a truncated icosahedron geometry, composed of pentagonal and hexagonal panels that are bolted together. This permits the radome (5.5 $\mathrm{m}$ at the equatorial point) to be broken down into pieces small enough to fit inside the shipping seatainers. The outside of the radome is covered with hydrophobic paint to avoid formation of water films that can lead to attenuation and distortion of dual polarization measurements.

The integrated radar shelter, radar platform, positioner, radome, INU, and dual-GPS receivers form a mechanically solid unit that is affixed to the deck of the research ship, mating to preexisting seatainer anchor positions. The entire assembly is rated to sustain winds in excess of $50 \mathrm{~m} \mathrm{~s}^{-1}(\sim 100 \mathrm{kt})$, not that such a wind speed would be intentionally encountered at sea. However, SEA-POL is also designed to operate on land, where such winds are possible.

The installation for the SPURS-2 cruise on the $\mathrm{R} / \mathrm{V}$ Roger Revelle is shown in Fig. 2, with the radar installed on the forward " 02 " deck. The reader may note this configuration is very different compared to previous radar installations, where the radar shelter was mounted on the deck with the antenna, pedestal,

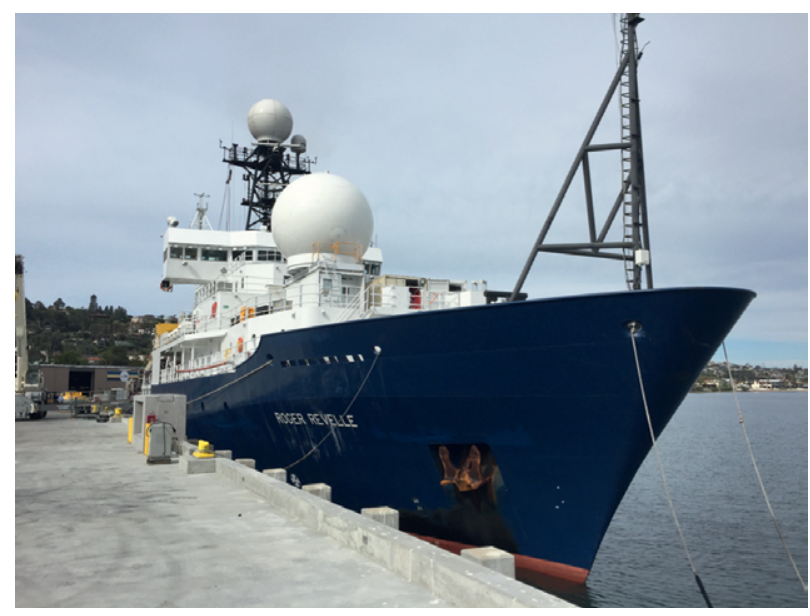

FIG. 2. Photo of SEA-POL mounted on the 02 deck of the R/V Roger Revelle in San Diego before departing on the SPURS-2 cruise. The SEA-POL radome is the large radome near the bow of the ship. The smaller radome mounted above the bridge houses the ship's satellite communications antenna. [Credit: Steven Rutledge; this figure is reprinted from Rutledge et al. (2019) under the terms of the Creative Commons Attribution 4.0 International License (https://creativecommons.org /licenses/by/4.0/).] and positioner mounted high above on top of the ship's bridge (the smaller radome in this position in Fig. 2 houses the ship's satellite communication antenna). Why was the installation on the R/V Roger Revelle so different? There are several reasons. First, when NSF was considering funding SEA-POL, we were asked to design an installation that would be economical and easily adaptable to various research ships. This precluded mounting the antenna atop the bridge, as each ship would have to be outfitted with a special platform to accept the radar antenna involving significant cost. In addition, the SEA-POL receiver and other sensitive electronics are located on the pedestal within the radome, by design. It is important that radar engineers have access to these components at sea. Such access is not typically allowed atop the ship's bridge during underway operations. The installation on the forward 02 deck provides quick access to these components through a custom designed radome hatch. Furthermore, when the antenna is mounted atop the bridge, the waveguide run is very long, which increases two-way losses that reduces radar sensitivity. As a result of this new configuration, the radar transmitter cannot be operated over a full $360^{\circ}$ azimuthal swath, as it is necessary to avoid illuminating the ship's bridge with RF energy. As a result, a $240^{\circ}$ sector centered on the ship's bow is scanned (the antenna sweeps through the full $360^{\circ}$ sector with the transmitter automatically blanked when the antenna is looking aft). A one-third reduction in the area covered by SEA-POL is not detrimental to collecting statistically robust data. Besides, the ship can always be turned to "face" interesting weather using its bow thrusters, provided this maneuver does not interfere with "over the side" measurements being done by other scientists. The operational characteristics of SEA-POL are summarized in Table 1.

In addition to the single-polarization measurements of horizontal reflectivity factor $\left(Z_{\mathrm{H}}\right)$, Doppler velocity $\left(V_{R}\right)$, and spectral width $(\sigma)$, SEA-POL collects dual-polarization measurements of differential reflectivity $\left(Z_{\mathrm{DR}}\right)$, copolar correlation coefficient at zero lag $\left(\rho_{\mathrm{HV}}\right)$, and differential phase $\left(\varphi_{\mathrm{DP}}\right)$. A full discussion of these polarimetric moments can be found in Bringi and Chandrasekar (2001) and Rauber and Nesbitt (2018). Differential reflectivity provides basic information on particle shape and phase and is a measure of the reflectivity-weighted mean axis ratio. The correlation coefficient is sensitive to particle phase and shape and identifies regions of mixed phase precipitation, including areas of melting ice particles, such as the radar bright band in stratiform 
TABLE I. SEA-POL specifications.

\begin{tabular}{|l|l|l|}
\hline \multicolumn{1}{|c|}{ Characteristic } & \multicolumn{1}{c|}{ Value } & \multicolumn{1}{c|}{ Remarks } \\
\hline Frequency & $5.4-5.75 \mathrm{GHz}$ & Tuning range of magnetron, nominally $5.65 \mathrm{GHz}$ \\
\hline Polarization modes & $\mathrm{H}$, simultaneous HV & Selectable on a scan-by-scan basis \\
\hline Antenna gain & $44.5 \mathrm{dBi}$ & At $5.65 \mathrm{GHz}$ \\
\hline Antenna beamwidth & $\mathrm{I}^{\circ}$ & Symmetric pencil beam on all planes \\
\hline Antenna sidelobe & $-27 \mathrm{~dB}$ & Typical one-way \\
\hline Cross-polarization isolation & $40 \mathrm{~dB}$ & Measured at boresight \\
\hline Transmit power & $250 \mathrm{~kW}$ & Nominal at $5.65 \mathrm{GHz}(\mathrm{I} 25 \mathrm{~kW}$ per channel, $\mathrm{H}$ and $\mathrm{V}$ ) \\
\hline Pulse repetition frequency & $300-\mathrm{I}, 800 \mathrm{~Hz}$ & \\
\hline Pulse width & $0.4-2 \mathrm{~ms}$ & \\
\hline Receiver bandwidth & $0.5-4 \mathrm{MHz}$ & Configurable depending on operating mode \\
\hline Receiver minimum detectable signal (MDS) & $-110 \mathrm{dBm}$ & At I MHz bandwidth \\
\hline
\end{tabular}

precipitation. Differential phase is sensitive to nonspherical particles and is an excellent discriminator between oblate raindrops and quasi-spherical ice particles like graupel. Therefore in mixed phase precipitation, differential phase (and its range derivative specific differential phase, $K_{\mathrm{DP}}$ ) is sensitive only to oblate rain and not quasi-spherical hail and graupel. In ice regions, positive $K_{\mathrm{DP}}$ can distinguish pristine, oriented ice from aggregates (Kennedy and Rutledge 2011). Another significant advantage of a dual-polarized radar is that the polarimetric fields can be used for calibration purposes (of reflectivity $Z$, based on $K_{\mathrm{DP}}$; Ryzhkov et al. 2005a) and attenuation correction (based on $\varphi_{\mathrm{DP}}$; Bringi and Chandrasekar 2001). Data quality is further improved by eliminating second trip and nonmeteorological echo such as sea clutter using polarimetric variables. These are a few reasons why a polarimetric radar like SEA-POL was developed for deployment on U.S. research ships.

Some discussion regarding the potential impact of ship motions on SEA-POL's polarimetric measurements, namely, $Z_{\mathrm{DR}}$ and $\varphi_{\mathrm{DP}}$, is warranted. Ship motions introduce deviations about the main beam (boresight) axis and rotation about the antenna elevation axis. These impacts have an equivalent effect of changing either the mean particle canting angle relative to the radar beam or the elevation angle of the antenna (it is well known that $Z_{\mathrm{DR}}$ observations are reduced by a few tenths of a $\mathrm{dB}$ when precipitation is viewed at sufficiently high elevation angles, say in excess of $20^{\circ}$ in rain; Ryzhkov et al. 2005a). The effects of ship motion on the polarimetric variables (or reorienting the $\mathrm{H}, \mathrm{V}$ polarization bases relative to true horizontal and vertical due to roll and pitch of the ship) can be understood by considering two examples. First, envision the radar scanning perpendicular to the long axis of the ship and the ship pitching up or down. Second, envision the ship rolling to port or starboard with the radar viewing precipitation directly ahead of the ship. Both examples serve to illustrate the impact of ship motion on rotating the $\mathrm{H}, \mathrm{V}$ transmit polarization bases. Apart from these simple geometrical examples, any combination of viewing angle, roll angle and pitch angle may be realized. For ground-based radars the polarimetric observations are made in the principal or so-called eigen polarization states of the precipitation volume, namely, the horizontal-vertical states. However, the actual polarization state may be different from the eigen polarization states due to pitch/roll motions on a ship. To evaluate the impact of pitch and roll, we simulated these effects by modeling changes in mean canting and elevation angle in simulated radar data. We evaluated the normalized error in $Z_{\mathrm{DR}}$ and $K_{\mathrm{DP}}$ for an assumed Gamma drop size distribution with the constraint that the rainfall rate is limited to $300 \mathrm{~mm} \mathrm{~h}^{-1}$ and reflectivity $Z$ is $<55 \mathrm{dBZ}$, parameters that adequately capture the range of these variables for oceanic convection. We can summarize the simulations with the following. As a specific example, consider an elevation angle of $5^{\circ}$ (close to the maximum elevation angle used in our SPURS-2 rain mapping scans; discussed below) with a moderate ship roll of $10^{\circ}$. This combination yields a normalized error in $Z_{\mathrm{DR}}$ of $0.1 \mathrm{~dB}$, in the worst-case scenario, when the radar views precipitation directly ahead of the ship. Hence for a $Z_{\mathrm{DR}}$ value of 1-2 dB in moderate rain, the absolute error in $Z_{\mathrm{DR}}$ due to ship motion is $0.1-0.2 \mathrm{~dB}$. In this same situation, $K_{\mathrm{DP}}$ may range from $2^{\circ}$ to $3^{\circ} \mathrm{km}^{-1}$ and the expected error in $K_{\mathrm{DP}}$ due to ship motion is $0.2^{\circ} \mathrm{km}^{-1}$. Research ships can certainly encounter rough sea states at times. To anticipate the magnitude of roll and pitch angles for 
rough seas, during the design phase of SEA-POL we examined roll and pitch data from the Gas Exchange Study (GasEx) cruise of the $R H B$, which took place in the Southern Ocean during austral winter in 2008. Under $20 \mathrm{~m} \mathrm{~s}^{-1}$ winds the extreme values of pitch and roll were $16.5^{\circ}$ and $24^{\circ}$, respectively. However, the frequency distributions of roll and pitch (not shown) indicated these extreme values were encountered less than $5 \%$ of the time (for a $24 \mathrm{~h}$ period during a highly disturbed period). So in nearly all seas states encountered by SEA-POL the errors in $Z_{\mathrm{DR}}$ and $K_{\mathrm{DP}}$ are sufficiently low such that polarimetric data of high quality can be expected for the purpose of rainfall estimation and hydrometeor identification (Bringi and Chandrasekar 2001; Ryzhkov et al. 2005b). These errors are also in close agreement with those recently reported by Thurai et al. (2014). For completeness we also conducted electromagnetic modeling studies of ice particles. For ice particles, the errors in differential reflectivity were less than $0.1 \mathrm{~dB}$ for the full range of ship motions encountered in GasEx. Likewise, the er-

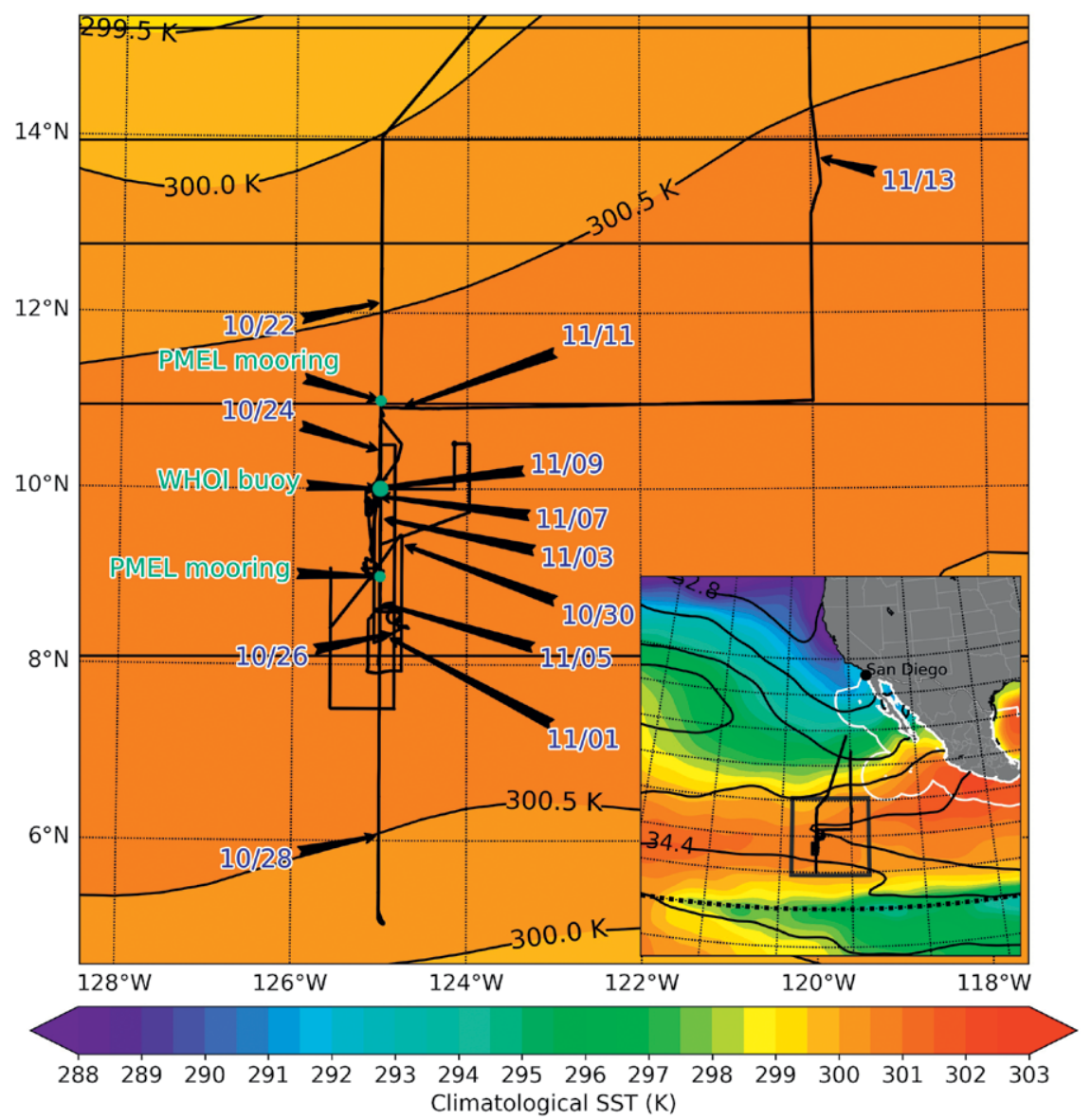

FIG. 3. Zoomed map of R/V Roger Revelle position during the SPURS-2 cruise with climatological SST for the cruise period (color filled). Inset depicts a zoomed-out map of R/V Roger Revelle position, with SST color filled and surface salinity contoured (climatological data). rors in $K_{\mathrm{DP}}$ were negligible, on the order of $0.01^{\circ} \mathrm{km}^{-1}$. Therefore SEA-POL measurements of $Z_{\mathrm{DR}}$ and $K_{\mathrm{DP}}$ in rain and ice provide robust scientific data and also serve as high-quality inputs to rainfall estimation and fuzzy logic-based hydrometeor identification algorithms.

\section{SPURS-2 CRUISE OVERVIEW. The SPURS-2} cruise departed San Diego on the morning of 17 October 2017 and arrived back there on the morning of 17 November 2017. The main scientific focus of this cruise was to study the fate of freshwater deposited on the ocean's surface in the form of rainfall. Of particular interest were "freshwater puddles" created by small to modest convective cells, which are typically accompanied by light winds. A key scientific thrust was to investigate the time scales over which these puddles are mixed out by wind and upper-ocean turbulence (Drushka et al. 2016). The freshwater puddles promote stabilization of the local ocean surface as lower-density rainwater sits atop higher density ocean water. The study site was centered at $10^{\circ} \mathrm{N}$, $125^{\circ} \mathrm{W}$, corresponding to the location of the Woods Hole Oceanographic Institution (WHOI) buoy. This buoy is strategically placed to be within the climatological rainfall maximum associated with the east Pacific ITCZ. In addition to the SEA-POL radar, the ship carried a large suite of oceanographic instruments for documenting the characteristics of freshwater puddles and the deeper ocean structure. These instruments included various types of drifters and floats, sea gliders and wave gliders, and continuous underway sampling of seawater via a "sea snake" [a boom mounted hose that collects seawater and pumps it to the ship's laboratory for real-time analysis of temperature $(T)$, salinity $(S)$, $p \mathrm{CO}_{2}$, and other chemical and biological properties]. Additional measurements 
included a full suite of meteorological and flux measurements mounted on the ship's bow-mounted jackstaff, through-hull sampling of $T$ and $S$ below the waterline and a bowmounted altimeter for measuring wave heights. Another novel feature of the SPURS-2 cruise was deployment of the University of Washington Applied Physics Laboratory's Surface Salinity Profiler (SSP; Asher et al. 2014). This surfboard-like instrument was deployed off the starboard side of the R/V Roger Revelle via the ship's crane and then towed parallel to the ship attached to a tether. The SSP measured $T$ and $S$ over the upper

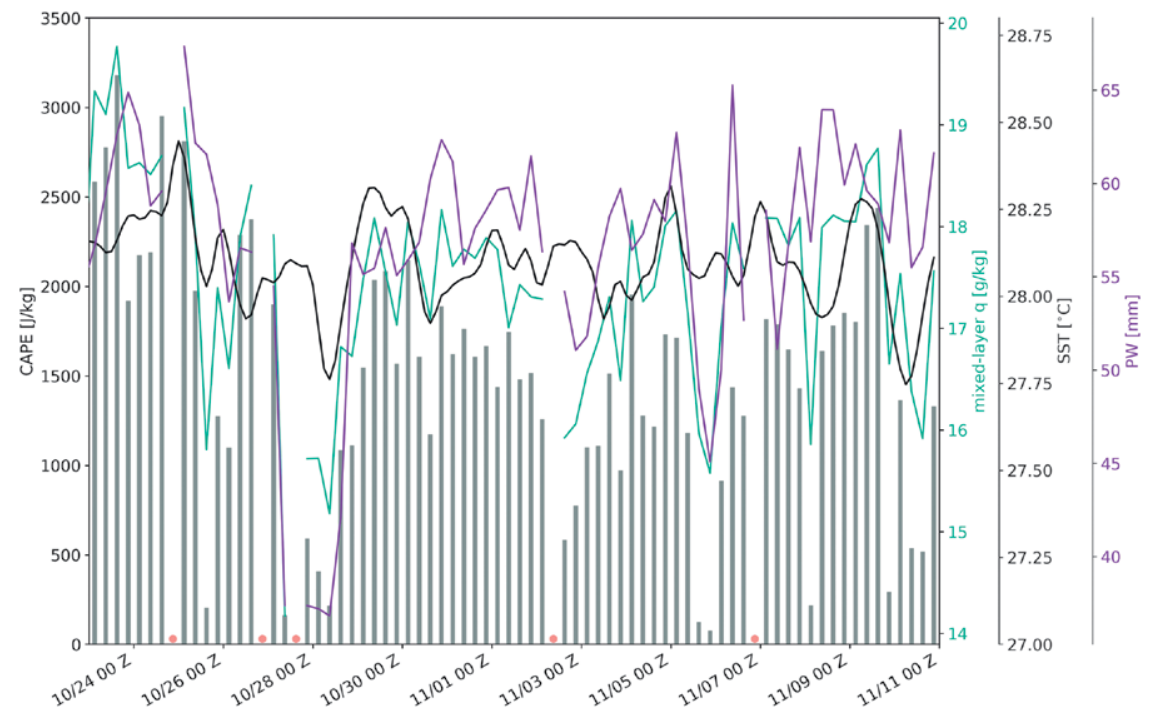

FIG. 4. Time series of convective available potential energy (CAPE; gray bars following the left axis), average specific humidity over the bottommost $50 \mathrm{hPa}$ (q; green line following the first right axis), sea surface temperature (black line; following the second right axis), and precipitable water (PW; purple line following the third right axis). CAPE, $q$, and PW were derived from 4-hourly soundings launched from the ship. SST measurements made directly by the R/V Roger Revelle. Red dots indicate missing sounding data from failed launches.

meter of the ocean. The

SSP was deployed for 12-h time blocks with the ship steaming at a slow speed of $4 \mathrm{kt}\left(2.1 \mathrm{~m} \mathrm{~s}^{-1}\right)$. In addition, conductivity-temperature-depth (CTD) profiles were obtained in a regular basis. To characterize the wind and thermodynamic profiles, four Vaisala RS-41 SG radiosondes were launched per day at 0300, 0900, 1500, and 2100 UTC. A disdrometer for measuring drop size distributions and rain rates at the ship was also deployed. Although we did not analyze data from most of these additional instruments for the present study, they provided extensive measurements of the sea and atmospheric state during the cruise. Furthermore, SEA-POL provided important rainfall context for various instruments, such as the SSP.

Figure 3 shows the position of the R/V Roger Revelle as a function of cruise day. On the way south from San Diego, the ship headed for $14^{\circ} \mathrm{N}, 125^{\circ} \mathrm{W}$ then cruised south along $125^{\circ} \mathrm{W}$, with small departures from that longitude over the research portion of the cruise. The ship reached $5^{\circ} \mathrm{S}$ at the southernmost point of the cruise. Near the end of the cruise, the $\mathrm{R} / \mathrm{V}$ Roger Revelle steamed east to $120^{\circ} \mathrm{W}$ to avoid a tropical depression before turning north toward San Diego. The color background of Fig. 3 shows the climatological mean SST for the October-November period, obtained from the NOAA Monthly Isopycnal/ Mixed-Layer Ocean Climatology (MIMOC) climatology (www.pmel.noaa.gov/mimoc). To provide additional meteorological perspective for the radar observations, Fig. 4 shows time series plots of CAPE, precipitable water (PW), and mixed layer specific humidity derived from the serial radiosonde data. SST measured by the R/V Roger Revelle at the time of each launch is also shown for context. CAPE was computed under pseudoadiabatic conditions, assuming a $50 \mathrm{hPa}$ deep mixed layer. At the beginning of the research component of the cruise (24 October 2017), CAPE, SST, specific humidity, and PW were all near peak values, and achieved local maximums again around 10 November, making conditions favorable for the developing tropical depression. In general CAPE values were large, with many soundings in excess of $2,000 \mathrm{~J} \mathrm{~kg}^{-1}$. These values may seem surprisingly high, but they are consistent with CAPE values from past tropical field projects [e.g., TOGA COARE (Petersen et al. 1996) and DYNAMO (Xu and Rutledge 2014)]. Convective motions in tropical clouds (summarized by Zipser and Lutz 1994) are nowhere near what is predicted by these CAPE values $\left[w_{\max } \sim(2 \mathrm{CAPE})^{1 / 2}\right]$. These large values of CAPE result from integrating modest thermal buoyancy over a very large depth between the lifted condensation level and the equilibrium level. These depths can easily be $12-13 \mathrm{~km}$ in the deep tropics. However, entrainment and mixing work as the primary means to reduce realizable CAPE, with water loading and hydrostatic pressure 
perturbations playing secondary roles (Wei et al. 1998; Morrison 2016).

RAINFALL MAPPING WITH SEA-POL. One of the critical contributions to the SPURS-2 cruise by SEA-POL was to map rainfall at fine spatial and temporal resolution, with special interest being paid to the establishment of freshwater puddles that form when compact rain cells dispense their precipitation to the ocean's surface. The distribution of rainfall around the ship, intensity (rain rate), and rain accumulations were of fundamental interest to the SPURS-2 oceanographic component. Oceanographers then used other instruments to measure the reduction in salinity with special interest to documenting the timeframe over which the salinity anomaly mixed out, as a function of wind speed and other factors (Drushka et al. 2016). To map rain, the $240^{\circ}$ sector was scanned at seven elevation angles ranging from $0.5^{\circ}$ to $4.75^{\circ}$. This volume scan allowed a (rectilinear) rain map to be produced at various heights ranging from $500 \mathrm{~m}$ near the ship to $2 \mathrm{~km}$ at long range $(120 \mathrm{~km})$, every five minutes. Immediately after each radar volume was collected, the raw polar data were filtered using a combination of simple thresholds and polarimetric-based algorithms to remove spurious and nonmeteorological echoes, including sea clutter. The algorithmic filtering consisted of a differential phase filter (which identified regions with high standard deviation of differential phase), and a despeckling filter (based on the texture of the reflectivity field). Once this initial filtering was done, additional filtering based on thresholds was applied using signal quality index (or normalized coherent power) less than 0.35 , signal to noise ratio less than $-5 \mathrm{~dB}$, and correlation coefficient $\left(\rho_{\mathrm{HV}}\right)$ less than 0.85 . Data points not satisfying these thresholds were flagged as bad. These thresholds are tunable to the specific radar and environment, which provides some flexibility to optimally filter the data in real time. Last, second-trip echoes were removed by identifying regions of smoothed signal quality less than 0.2. Fields of $Z$ and $Z_{\mathrm{DR}}$ were then corrected for attenuation using differential phase (Bringi and Chandrasekar 2001; Wang and Chandrasekar 2009). Finally the $Z_{\mathrm{DR}}$ field was corrected for a stable bias of $-0.3 \mathrm{~dB}$. This bias was arrived at by doing "bird bath" scans at sea, where the antenna is elevated to the maximum elevation angle of $85^{\circ}$ while continuously rotating in azimuth during instances of light rain. Once the data were quality controlled and attenuation corrected, the resultant fields were interpolated to a rectilinear grid for further processing, including generation of rain maps. Both raw and processed data are archived for future analysis.
Gridded rain rates were determined by using $Z$ as well as two of SEA-POL's polarimetric variables, $Z_{\mathrm{DR}}$ and $K_{\mathrm{DP}}$, the latter derived from differential phase; $Z_{\mathrm{DR}}$ is defined as a log ratio of the return power at horizontal polarization to vertical polarization. Ice particles such as graupel, hail, and snow aggregates have $Z_{\mathrm{DR}}$ values near zero owing to their relatively low dielectric constant and increased tumbling/chaotic orientations. Differential phase $\varphi_{\mathrm{DP}}$ is the measured phase shift between $\mathrm{H}$ and $\mathrm{V}$ waves propagating simultaneously through precipitation. In-depth explanations of differential phase can be found in Bringi and Chandrasekar (2001) and Kumjian (2018). The reader is directed to these references for a complete description of each polarimetric variable discussed here. Specific differential phase $K_{\mathrm{DP}}$ is derived by first filtering and smoothing the differential phase field since it is an inherently noisy measurement (Wang and Chandrasekar 2009). After filtering, $K_{\mathrm{Dp}}$ is derived by taking the range derivative of the smoothed differential phase field and multiplying by a factor of $1 / 2$, accounting for the fact that the phase shift occurs as $\mathrm{H}$ and $\mathrm{V}$ waves propagate to and from precipitation targets. Positive $K_{\mathrm{DP}}$ occurs when $\mathrm{H}, \mathrm{V}$ waves move through oblate targets, like raindrops. In ice, the phase shift is near zero for quasispherical ice particles. For prolate ice particles such as ice needles and columns, $K_{\mathrm{DP}}$ is $<0$ when these particles are oriented into the vertical, usually by a strong vertically oriented electric field generated by noninductive charging. Typical values of $K_{\mathrm{DP}}$ at $\mathrm{C}$ band in moderate to heavy rain are $2^{\circ}-4^{\circ} \mathrm{km}^{-1} ; K_{\mathrm{DP}}$ is a function of both particle oblateness and liquid water content (Bringi and Chandrasekar 2001). Note that a large value of $K_{\mathrm{Dp}}$ can be due mainly to oblateness or, for the case of near spherical drops, by high liquid water content (mass of water per unit volume). The latter is a frequent observation in the tropics, where convective cells often contain a large concentration of modest-sized drops constituting large liquid water contents, leading to heavy rainfall (Thompson et al. 2015, 2018).

The algorithm used to estimate rain rates was developed over the course of several years of research at CSU (Thompson et al. 2018). The basis for this algorithm was provided by several previous studies including Ryzhkov et al. (2005b) and Cifelli et al. (2011). Figure 5 shows the SEA-POL rain-mapping algorithm adapted from Thompson et al. (2018). This algorithm was developed using simulated polarimetric measurements from thousands of 1 min tropical drop size distribution (DSD) data collected during the DYNAMO (central Indian Ocean) field campaign and over a multi-year time period at Manus Island (courtesy of the DOE ARM program). Surface-based disdrometers 
provided the DSD measurements. Thus, this algorithm is especially applicable to tropical oceanic environments. The algorithm is applied to each grid point, using the quality-controlled radar data. The decision tree begins by examining $K_{\mathrm{DP}}$. If $K_{\mathrm{DP}}<0.3^{\circ} \mathrm{km}^{-1}$, then the rain estimate defaults to either a power law estimate relating reflectivity to rain rate (light rain; so-called $Z-R$ estimator) or a $R-Z-Z_{\mathrm{DR}}$ (moderate rain) estimator. This is because a $K_{\mathrm{DP}}$ value of $0.3^{\circ} \mathrm{km}^{-1}$ is considered to be the smallest value that can be accurately measured by SEA-POL. Note that in this algorithm, differential reflectivity is used in linear form $\left[\zeta_{\mathrm{DR}} ; \zeta_{\mathrm{DR}}=10^{\left(0.1 Z_{\mathrm{DR}}\right)}\right]$ to provide more precision compared to the log form, $Z_{\mathrm{DR}}$. When the $Z-R$ estimator is used, we used the so-called $Z-R$ ALL estimator [see Thompson et al. (2018) for more discussion on this], which is a $Z-R$ fit to all DSD data, that is, the data are not separated into convective and stratiform components. For more intense rainfall where sufficient differential reflectivity and differential phase occur, the $R-K_{\mathrm{DP}}-\zeta_{\mathrm{DR}}$ estimator is utilized. Practically speaking, this is rainfall from convective cells. This particular estimator requires a bit more explanation. Consider the case when $K_{\mathrm{DP}}$ is large and $Z_{\mathrm{DR}}$ is slightly positive. In this situation, since $R$ is inversely proportional to $Z_{\mathrm{DR}}$ in this estimator, $R$ is increased due to high liquid water contents reflected in the measurement of $K_{\mathrm{DP}}$. On the other hand, for the same $K_{\mathrm{DP}}$ but large $Z_{\mathrm{DR}}, R$ is decreased, as there is a larger contribution to $K_{\mathrm{DP}}$ from particle oblateness and less from liquid water content. The polarimetric estimators from SEA-POL provide robust rain estimates, even considering small errors in $Z_{\mathrm{DR}}$ and $K_{\mathrm{DP}}$ introduced by ship motions (discussed earlier). Based on Thompson et al. (2018), (C band) RMSE using the $R-Z-Z_{\mathrm{DR}}$ estimator is $2 \mathrm{~mm} \mathrm{~h}^{-1}$; for the $R-K_{\mathrm{DP}}-Z_{\mathrm{DR}}$ estimator, RMSE is $1.6 \mathrm{~mm} \mathrm{~h}^{-1}$. These errors are considerably less than the RMSE associated with a $Z-R$ estimator, $6 \mathrm{~mm} \mathrm{~h}^{-1}$. Indeed, bringing the polarimetric technology to sea in the form of SEA-POL was partly motivated by needing more accurate rain estimates over the oceans.

An example of the central output of the algorithm is provided in Fig. 6, showing instantaneous rain rates, rain accumulation maps, and the "age" of rain. These fields were displayed in near-real time on a large monitor in the ship's main laboratory so that oceanographers could be constantly aware of the rainfall patterns and intensities around the ship. When the radar data indicated that rainfall had recently fallen near the ship, the ship would often deviate slightly to intercept the resulting fresh puddles. The time lag between acquiring the raw data and displaying the final fields as illustrated by Fig. 6 was approximately $2 \mathrm{~min}$. These real-time rain maps were a novel component of the SPURS-2 deployment of SEA-POL.

The SPURS-2 deployment of SEA-POL provided a first opportunity to utilize polarimetric observations at sea to derive rainfall statistics. Before discussing a few statistics, we first comment on application of the Thompson et al. (2018) algorithm in this tropical rain regime. It is interesting to see how often each logic pathway (rain estimator) is used in the algorithm, and what volume of rainfall is associated with that particular estimator. Figure 7 summarizes these statistics. For the sake of this discussion, we purposely made no attempt to partition the reflectivity data into convective and stratiform components, which is traditionally done in order to apply specific $Z-R$ rain mapping relations to the partitioned reflectivity data. Such separation is not required for the polarimetricbased estimators. Rather our goal here to assess the frequency of each pathway in Fig. 5 and to quantify the rain volume associated with each pathway. And 
importantly, to cull out the rain fraction mapped by polarimetric estimators provided by SEA-POL versus the nonpolarimetric $Z-R$ ALL estimator. First, the $R-Z-\zeta_{\mathrm{DR}}$ and $R-Z$ estimators were used roughly at the same frequency ( $50 \%$ vs $45 \%$, respectively; Fig. $7 \mathrm{a})$. The remaining $\sim 4 \%$ of the grid points used the $R-K_{\mathrm{DP}}-\zeta_{\mathrm{DR}}$ pathway. This pales in comparison to the previous two estimators. Practically speaking, the $R-K_{\mathrm{DP}}$ estimator was not used. This method occurs only when $K_{\mathrm{DP}}$ is above the $0.3^{\circ} \mathrm{km}^{-1}$ yet $Z_{\mathrm{DR}}$ is near zero, a common occurrence in the midlatitudes when hail and rain are present in the same volume, but a rare occurrence in the tropics. We now turn to a discussion of the rain volumes associated with each pathway (Fig. 7b). Although the $R-Z$ method was used quite frequently (applied in light rain that had very small $K_{\mathrm{DP}}$ and $Z_{\mathrm{DR}}$ ), the rain associated with these grid points constituted just $13 \%$ of the total rain volume sampled on the cruise. On the other hand, $37 \%$ of the total rain volume was mapped by the $R-Z-\zeta_{\mathrm{DR}}$ method. The most striking feature of Fig. $7 \mathrm{~b}$ pertains to the $R-K_{\mathrm{DP}}-\zeta_{\mathrm{DR}}$ estimator. We noted above that $4 \%$ of the grid points utilized this method, yet these relatively few grid points accounted for nearly onehalf of the total rain volume in SPURS-2! This rain is from intense convective cores and underpins the utility of polarimetric measurements from SEA-POL in capturing this important component.

\section{SEAPOL: 2017-10-26 00:25:03 rainfall}

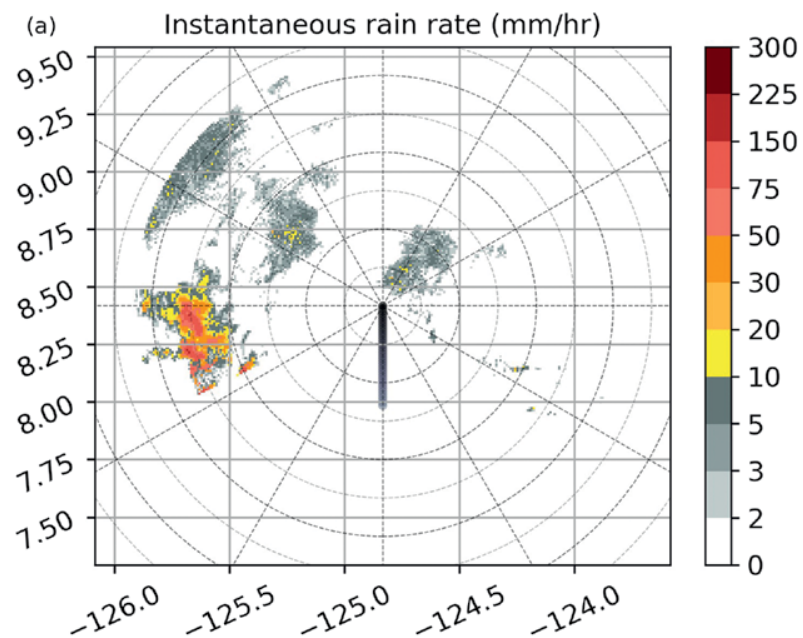

(b) Rainfall age (min) using $10 \mathrm{~mm} / \mathrm{hr}$ threshold

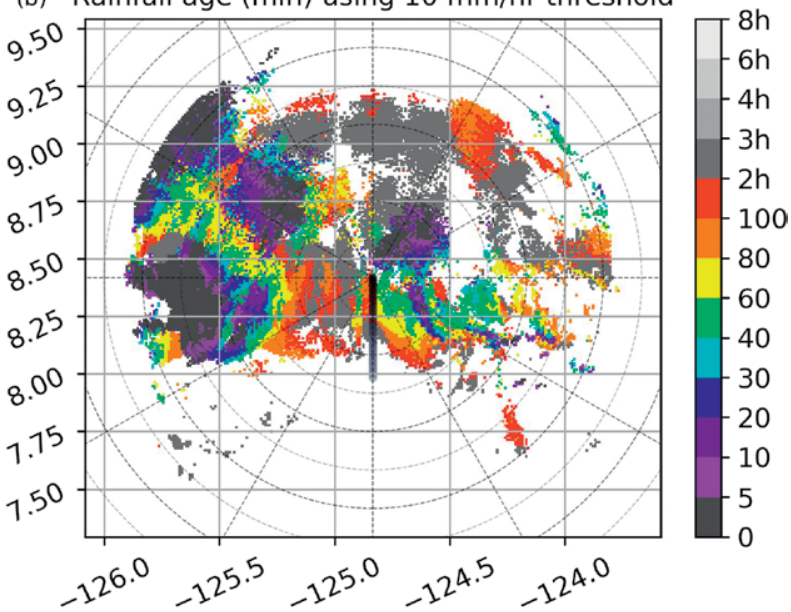

(c) 30 min rainfall accumulation $(\mathrm{mm})$

(d) 60 min rainfall accumulation $(\mathrm{mm})$
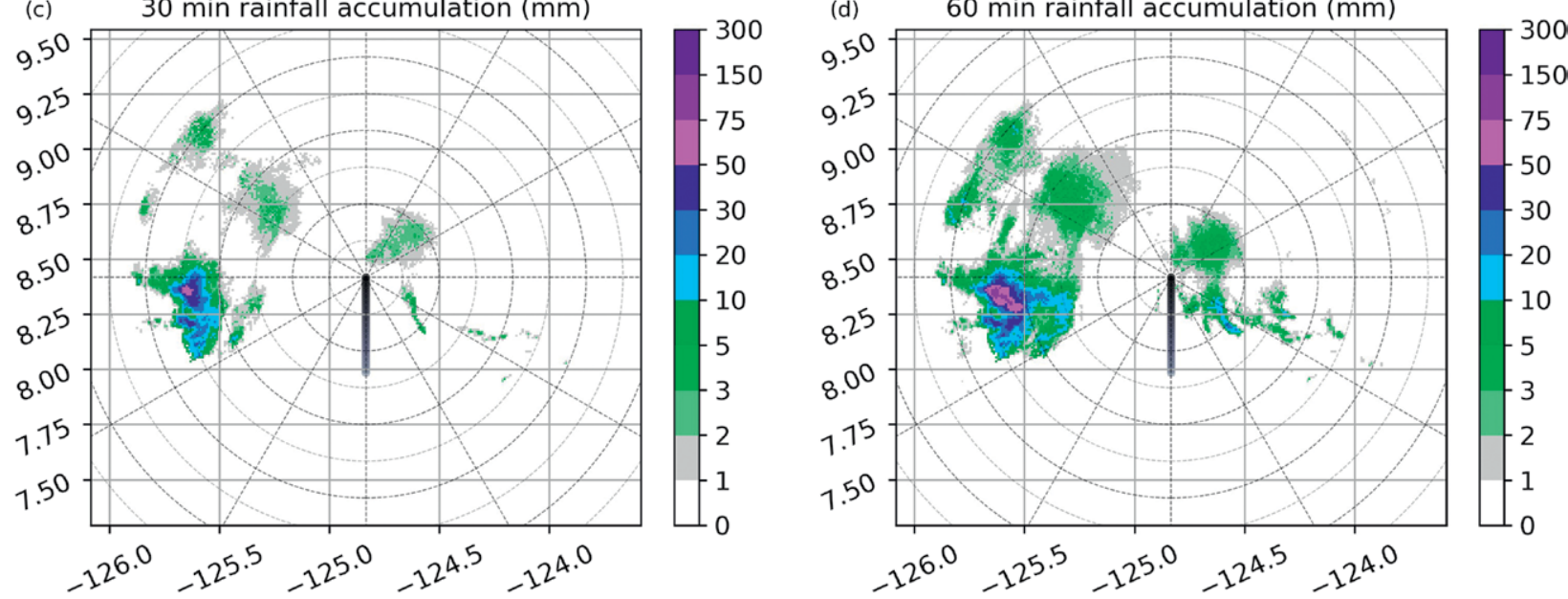

FIG. 6. (a) Instantaneous rain rate (color fill) computed for the 5 -min radar volume collected at $0025 \mathrm{UTC}$ 26 Oct 2017. The position of the ship for the previous $6 \mathrm{~h}$ is indicated with the black dots. Range rings are shown for each 10 nautical miles $\left(\mathrm{n} \mathrm{mi}\right.$; I $\mathrm{n} \mathrm{mi}=1.852 \mathrm{~km}$ ). (b) Elapsed time since a rain rate of at least $10 \mathrm{~mm} \mathrm{~h}^{-1}$ was observed at a given latitude-longitude point. (c) 30 -min accumulated rainfall at a given latitude-longitude point. (d) 60-min accumulated rainfall at a given latitude-longitude point. Latitude is north (y axis) and longitude is west ( $x$ axis). [This figure is reprinted from Rutledge et al. (2019) under the terms of the Creative Commons Attribution 4.0 International License (https://creativecommons.org/licenses/by/4.0/).] 
We conclude this section by diving a little deeper into the SEA-POL polarimetric data from SPURS-2 by examining scatterplots of reflectivity and polarimetric parameters for convective and stratiform precipitation (Fig. 8). For this purpose, we applied the Steiner et al. (1995) Z-based partitioning algorithm to "loosely" break out the polarimetric observations into convective and stratiform components. We are not concerned here about relative amounts of convective and stratiform rain, or fringe/hybrid echo as other schemes might identify (e.g., Powell et al. 2016); merely, we just desire to separate the data into these two gross components to identify basic microphysical distinctions. In fact, the clear distinction between convective and stratiform populations in Fig. 8 adds creditability to using the Steiner et al. (1995) method for this discussion. We examine relationships between $Z$ and $K_{\mathrm{DP}}, K_{\mathrm{DP}}$ and $Z_{\mathrm{DR}}$, and $Z$ and $Z_{\mathrm{DR}}$. These plots were made by using all data from the SPURS-2 PPI scans (that ran continuously during the 20 days of the cruise's research phase, at a repeat cycle of $5 \mathrm{~min}$ ), limited in height to $4 \mathrm{~km}$ to avoid contamination from ice particles (during the cruise the $0^{\circ} \mathrm{C}$ level was approximately $4.8 \mathrm{~km} \mathrm{MSL}$ ). Figure 8 top (bottom) panels show the convective

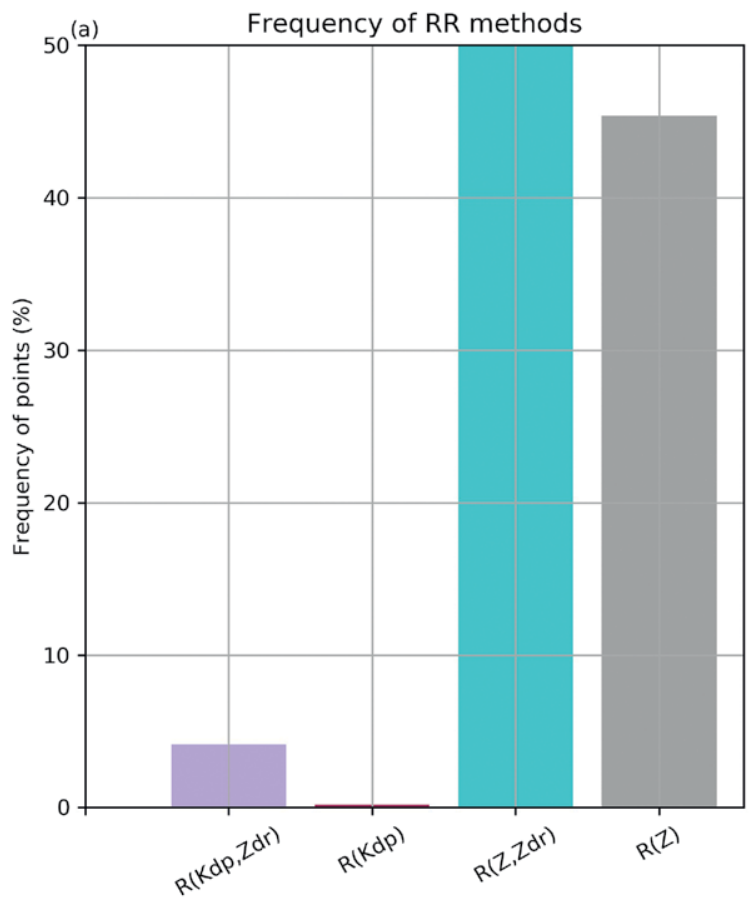

(stratiform) distributions. The contours in these plots represent normalized frequency of occurrence values of $0.1 \%, 1 \%$, and $10 \%$. The $K_{\mathrm{DP}}-Z$ plot (Fig. $8 \mathrm{a}$, convective) shows a sharp increase in $K_{\mathrm{DP}}$ with increasing $Z$. This reflects higher water contents and larger, oblate raindrops at higher $Z$, since $K_{\mathrm{DP}}$ depends on both liquid water content and particle oblateness. However, although the population is small, evidently large drops (as indicated by the coincident values of $Z_{\mathrm{DR}}>2 \mathrm{~dB}$ colored in red) promote large $Z$ with very low values of $K_{\mathrm{DP}}$. There are at least two explanations of this behavior; size sorting on the edge of convective cores (Kumjian and Ryzhkov 2012; large drops falling out in the absence of small drops) and the occurrence of shallow, warm rain convective cells where coalescence rapidly produces large drops but evidently small water contents. Values of $Z_{\mathrm{DR}}$ of $2-3 \mathrm{~dB}$ are associated with individual drops of 3.5-4.5 mm equivalent diameter (Herzegh and Jameson 1992), and median drop diameters of $2-3 \mathrm{~mm}$ at $\mathrm{C}$ band (Bringi et al. 2009). The convective $K_{\mathrm{DP}}-Z_{\mathrm{DR}}$ plot (Fig. 8b) has a bell-shaped distribution. For a $Z_{\mathrm{DR}}$ value of $1 \mathrm{~dB}$ (drop diameters of 2-2.5 mm), a large range of $K_{\mathrm{DP}}$ values are possible, spanning a considerable range rain of $Z$ (indicated by the color shading).

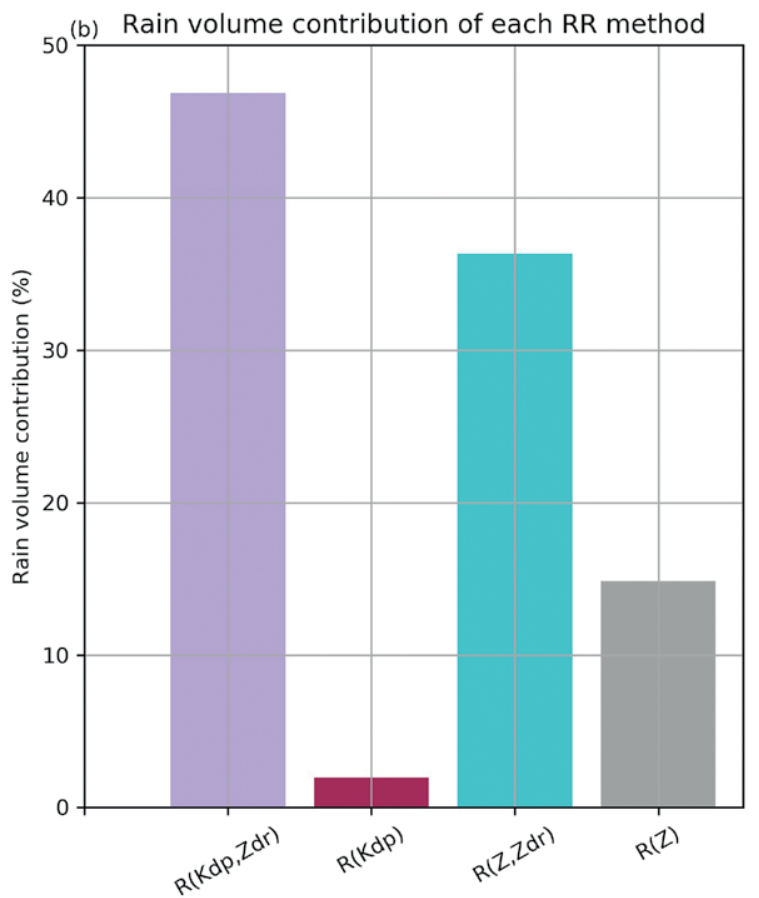

FIG. 7. (a) Percentage of radar grid points classified by the individual rain-rate algorithm branches shown in Fig. 5. For example, the $R-Z-\zeta_{D R}$ estimator was used at $50 \%$ of the raining grid points. The frequency for all bars sums to $100 \%$. (b) Rain volume in percent tied to each rain-rate algorithm branch. Although the $R-K_{D P}-\zeta_{D R}$ estimator was used at $4 \%$ of the raining grid points, those points composed roughly $45 \%$ of the total rain volume. The $R-Z$ estimator was used fairly frequently (about $45 \%$ ) yet the rain volume contributed by those points was less than $15 \%$ of the total rain. 
The large range of $K_{\mathrm{DP}}$ for $Z_{\mathrm{DR}}=1 \mathrm{~dB}$ is associated with large variations in rainwater liquid water content, which implies a large range of rain rates around this particular value of $Z_{\mathrm{DR}}$. For example, assuming $Z_{\mathrm{DR}}=1 \mathrm{~dB}$ the rain rate given by the $R-\zeta_{\mathrm{DR}}-K_{\mathrm{DP}}$ relationship varies from $17 \mathrm{~mm} \mathrm{~h}^{-1}\left(K_{\mathrm{DP}}=1^{\circ} \mathrm{km}^{-1}\right)$ to $57 \mathrm{~mm} \mathrm{~h}^{-1}\left(K_{\mathrm{DP}}=2^{\circ} \mathrm{km}^{-1}\right)$. Evidently, in intense convective rain shafts, drop diameters are modest and rain rate is strongly controlled by liquid water content; such information is not available from single polarization radars, which again highlights the utility of SEA-POL for studying oceanic convection. The $Z_{\mathrm{DR}}-Z$ scatterplot (Fig. $8 \mathrm{c}$ ) shows the relationship between drop size and reflectivity. We can compare this plot to Fig. 4 from Ryzhkov et al. (2005c). Their $Z-Z_{\mathrm{DR}}$ scatterplot was acquired in a dissipating tropical storm over Oklahoma, which they defined as "tropical rain." Although the range of reflectivities was similar to those in Fig. 8b, the range of $Z_{\mathrm{DR}}$ values are considerably larger $(>1.5 \mathrm{~dB})$ in the SPURS-2 sample, although these larger $Z_{\mathrm{DR}}$ values are rather infrequent. This contrast is perhaps expected as in the deep tropics large drops can rapidly form via coalescence associated with low CCN concentrations. The stratiform distributions (Figs. 8d-f) are constrained relative to the convective distributions. The $K_{\mathrm{DP}}$ values are small in stratiform rain, even at relatively high $Z$ (Fig. 8d). Examining Fig. $8 \mathrm{f}$ $\left(Z_{\mathrm{DR}}\right.$ vs $\left.Z\right)$, large $Z_{\mathrm{DR}}$ values are occasionally observed at moderate $Z$ (but low $K_{\mathrm{DP}}$ ). We suggest this is the result of aggregation in the ice portions of tropical clouds. These aggregates then melt to produce oblate raindrops, indicated by the high $Z_{\mathrm{DR}}$ values with low liquid water contents as revealed by $K_{\mathrm{DP}}$. One final
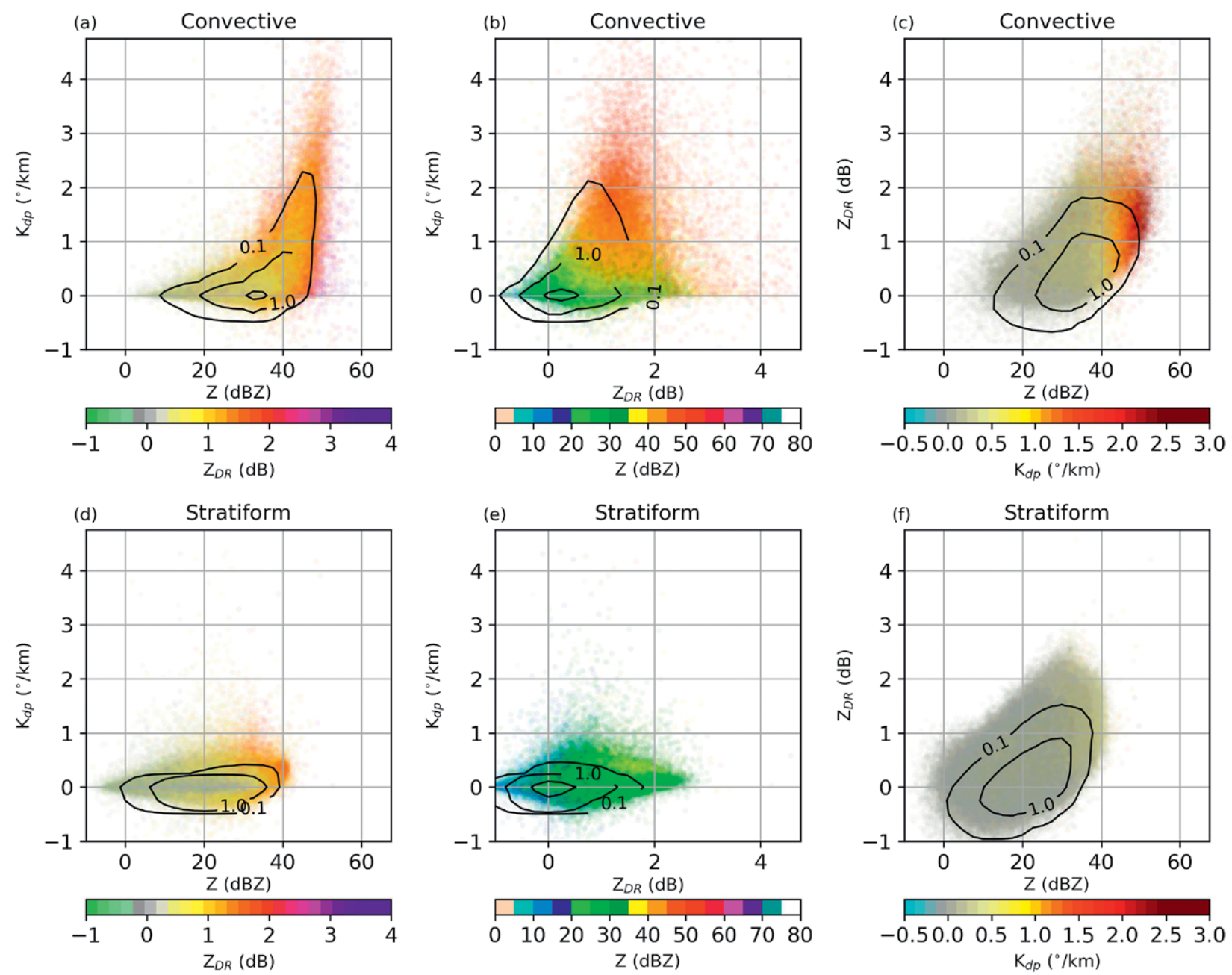

FiG. 8. (a) Scatterplot of reflectivity ( $Z$ in log units) and specific differential phase $\left(K_{\mathrm{dp}}\right)$ points colored by differential reflectivity $\left(Z_{D R}\right)$ for convective points. (b) Scatterplot of $Z_{D R}$ and $K_{d p}$ points colored by $Z$ for convective points. (c) Scatterplot of $Z$ and $Z_{D R}$ points colored by $K_{D P}$ for convective points. (d) As in (a), but for stratiform points. (e) As in (b), but for stratiform points. (f) As in (c), but for stratiform points. The contours indicate probability distribution frequencies of $0.1 \%, 1.0 \%$, and $10.0 \%$. 
comment considering the distribution of $Z_{\mathrm{DR}}$ and $K_{\mathrm{DP}}$ (Fig. 8b). The highest frequency of occurrence is near zero for both $Z_{\mathrm{DR}}$ and $K_{\mathrm{DP}}$, with reflectivities near 30-35 dBZ resulting in modest convective rain rates ranging from 4 to $9 \mathrm{~mm} \mathrm{~h}^{-1}$. Significantly positive values of $Z_{\mathrm{DR}}$ and $K_{\mathrm{DP}}$ occur far less frequently. However, it is these "outlier" values that map large convective rain rates $\left(>20 \mathrm{~mm} \mathrm{~h}^{-1}\right)$, which dominate the convective rain volume (Fig. $7 \mathrm{~b}$ ).

MICROPHYSICAL STRUCTURES OBSERVED BY SEA-POL. In this section we use the Doppler and polarimetric capabilities of SEA-POL to illustrate the kinematic and microphysical structures for two precipitation events observed during SPURS-2. The Dolan et al. (2013) C-band 10-category fuzzy logic hydrometeor classification algorithm (HID) was applied to the SEA-POL data with two important modifications. First, trapezoidal membership functions were created for temperature, generally following the inflection points of the beta functions defined in Dolan et al. (2013). The trapezoidal shapes allow for penalizing certain hydrometeor types at improbable temperatures by assigning a value of -1 rather than 0 . These penalties were determined somewhat subjectively based on published temperature ranges of hydrometeor types. With these functions for temperature, linear weighting in the fuzzy logic scoring can be utilized, allowing for more influence of the polarimetric information without stratification that sometimes results from the heavy temperature weighting required to separate frozen and liquid hydrometeor types. Second, the melting layer (wet snow) was identified through application of the first step of the Thompson et al. (2014) algorithm, which distinguishes wet snow from other categories without the use of temperature. This methodology more accurately identifies the melting layer compared to the wet snow category in Dolan et al. (2013), thereby reducing the misclassifications of high-density graupel that is often noted in intense tropical bright bands.

Figure 9 shows a cross section through a warm rain cell, which were ubiquitous over the warm waters of the tropical east Pacific. With cloud base at $800 \mathrm{~m} \mathrm{MSL}$ and the melting level at $4.8 \mathrm{~km}$ MSL (from the SPURS-2 sounding data), the bulk of this echo can be classified as warm rain. Both $Z$ and $Z_{\mathrm{DR}}$ increase downward to the surface, indicating continued coalescence growth (Kumjian and Prat 2014). Maximum $Z_{\mathrm{DR}}$ values near the surface approach $2 \mathrm{~dB}$,

FIG. 9. Range-height indicator (RHI) plots of (a) reflectivity, (b) Doppler radial velocity corrected for storm motion, (c) differential reflectivity, (d) copolar correlation coefficient, (e) specific differential phase, and (f) hydrometeor classification at 18I2:54 UTC 28 Oct 2017 facing east (84 ${ }^{\circ}$ azimuth). 
indicative of drops with equivalent volume diameters of $\sim 3.5 \mathrm{~mm}$. Modest $K_{\mathrm{DP}}$ values of $1^{\circ} \mathrm{km}^{-1}$ are evident in the most intense portion of the rain area, roughly $30-35 \mathrm{~km}$ range. The HID is dominated by rain in the main precipitation area. Drizzle/light rain are inferred above rain, which makes sense as small droplets transition into larger raindrops via coalescence. The HID indicates some portions of the warm rain cell are apparently frozen with identification of ice aggregates (likely nonpristine ice particles).

Figure 10 shows a strong convective cell, which produced lightning near the ship (in general lightning was very rare during the cruise). CAPE ranged from 1,500 to $2,000 \mathrm{~J} \mathrm{~kg}^{-1}$ prior to cell development (Fig. 4). Radial velocity (Fig. 10b, storm relative) shows strong low-level convergence (at $\sim 15 \mathrm{~km}$ range), as the easterly trade winds (inbound velocities) met the storm inflow. New cell development is evident between 15 and $20 \mathrm{~km}$ range. The mature cell is centered near $30-35 \mathrm{~km}$ range. Both the developing cell and the mature cell appear highly sheared, consistent with the transition from easterly to westerly flow around $2.5 \mathrm{~km} \mathrm{MSL}$. Significant $Z, K_{\mathrm{DP}}$ and $Z_{\mathrm{DR}}$ values are found near $30 \mathrm{~km}$ range, where the most intense rain is occurring (rain rate $\sim 60 \mathrm{~mm} \mathrm{~h}^{-1}$ ). The microphysical structure aloft at subfreezing temperatures is quite interesting. The center of the mature core is identified as low-density graupel (which is a necessary ingredient for electrification and lightning production) marked by relatively high $Z$ and near zero values of $K_{\mathrm{DP}}$ and $Z_{\mathrm{DR}}$. This area is enshrouded by positive $K_{\mathrm{DP}}$ and positive $Z_{\mathrm{DR}}$, a signature attributable to horizontally oriented ice crystals (Kennedy and Rutledge 2011; Kumjian and Lombardo 2017). This pattern is similar to that reported by Barnes and Houze (2014) for convection over the central Indian Ocean observed during DYNAMO. Although generating cells in winter storms are much smaller in scale, there are microphysical similarities between those structures and the convective cell shown in Fig. 10. Kumjian et al. (2014) reported that the core of generating cells was marked by high $Z$ and near zero $Z_{\mathrm{DR}}$ and $K_{\mathrm{DP}}$. Furthermore, the core of the generating cell was enshrouded by high $Z_{\mathrm{DR}}$, modest $K_{\mathrm{DP}}$, and reduced $Z$, which is very similar to the patterns described here. These two examples illustrate how the shipmounted SEA-POL radar can be used to provide microphysical insights into oceanic convection.

CONCLUSIONS. We have described the development and deployment of 
the technologically advanced SEA-POL radar. SEAPOL represents the first polarimetric weather radar deployed on a U.S. research ship. Two polarimetric seaworthy C-band radars preceded SEA-POL, those being radars on the R/V Mirai (Japan) and the R/V Investigator (Australia). The SPURS-2 deployment of SEA-POL was very successful, and served to demonstrate that high-quality polarimetric data can be collected at sea, despite the radar operating on a platform that is subject to constant ship motion. Our rainfall estimates are based on the Thompson et al. (2018) algorithm that relies heavily on polarimetric variables to estimate rain rates. Given that the $R-Z-$ $Z_{\mathrm{DR}}$ estimator is sensitive to small errors or biases in $Z_{\mathrm{DR}}$, mapping rainfall based on an $R(A)$ algorithm, where $A$ is the attenuation by scattering and absorption of rain, should also be considered (Ryzhkov et al. 2014). In SPURS-2, SEA-POL provided high-quality rain maps to allow oceanographers to deploy their temperature and salinity measuring instruments to sample newly established freshwater puddles. SEAPOL also afforded an opportunity to collect polarimetric observations of tropical convection, along with a variety of polarimetrically derived statistics relating to precipitation physics. SEA-POL just completed a very successful second deployment, Propagation of Intraseasonal Tropical Oscillations (PISTON), operating on board the R/V Thomas G. Thompson in the west Pacific region from mid-August to mid-October 2018. During PISTON we also had the novel opportunity to collect dual-Doppler observations working with the R/V Mirai. SEA-POL is now a proven asset for the U.S. research community and is available for ship-based and land-based field projects.

ACKNOWLEDGMENTS. First, we acknowledge the National Science Foundation and Colorado State University for providing the financial support for designing and constructing the SEA-POL radar. NSF support was provided by the MRI Grant AGS-1531714. Also, we thank NOAA for donating the former R/V Ronald H. Brown radar to CSU to motivate the SEA-POL development project. NASA and NSF provided support to CSU for the SPURS-2 deployment via a NASA Rapid Response Award (80NSSC17K0239) and an NSF Eager Award (AGS-1742760). Sounding data were acquired during the cruise by WHOI personnel (led by J. Edson and C. A. Clayson). Paul Ciesielski expertly quality controlled the sounding data at CSU. Our sincere thanks and appreciation go to the shore staff and ship's crew of the R/V Roger Revelle ably led by Captain David Murline. All were very helpful and very accommodating, and very receptive of having that "big white ball" on the front of their ship. We thank the external review committee that visited CSU during the critical design phase of SEA-POL, R. Carbone (NCAR), N. Bharadwaj (DOE/PNNL), and T. Lyly (Vaisala, Helsinki). The reviewers offered very insightful and constructive comments that greatly improved the manuscript and we thank them for their contributions. The late Bob Bowie made very important contributions to the design and development of SEA-POL. Bob's contributions to meteorological ship radars started with TOGA COARE in 1992. His contributions will always be remembered.

\section{REFERENCES}

Asher, W. E., A. T. Jessup, R. Branch, and D. Clark, 2014: Observations of rain-induced near-surface rain anomalies. J. Geophys. Res. Oceans, 119, 5483-5500, https://doi.org/10.1002/2014JC009954.

Barnes, H. C., and R. A. Houze Jr., 2014: Precipitation hydrometeor type relative to the mesoscale airflow in mature oceanic deep convection of the MaddenJulian oscillation. J. Geophys. Res. Atmos., 119, 13990-14014, https://doi.org/10.1002/2014JD022241.

Bringi, V. N., and V. Chandrasekar, 2001: Polarimetric Doppler Weather Radar: Principles and Applications. Cambridge University Press, 636 pp.

—, C. R. Williams, M. Thurai, and P.T. May, 2009: Using dual-polarized radar and dual-frequency profiler for DSD characterization: A case study from Darwin, Australia. J. Atmos. Oceanic Technol., 26, 2107-2122, https://doi.org/10.1175/2009JTECHA1258.1.

Carey, L. C., and W. A. Petersen, 2015: Sensitivity of C-band polarimetric radar-based drop size estimates to maximum diameter. J. Appl. Meteor. Climatol., 54, 1352-1371, https://doi.org/10.1175/JAMC -D-14-0079.1.

Cifelli, R. C., V. Chandrasekar, S. Lim, P. C. Kennedy, Y. Wang, and S. A. Rutledge, 2011: A new dual-polarization radar rainfall algorithm: Application in Colorado precipitation events. J. Atmos. Oceanic Technol., 28, 352-354, https://doi.org/10.1175/2010JTECHA1488.1.

DeMott, C. A., and S. A. Rutledge, 1998: The vertical structure of TOGA COARE convection. Part I: Radar echo distributions. J. Atmos. Sci., 55, 2730-2747, https://doi.org/10.1175/1520-0469 (1998)055<2730:TVSOTC >2.0.CO;2.

Dolan, B., S. A. Rutledge, S. Lim, V. Chandrasekar, and M. Thurai, 2013: A robust C-band hydrometeor identification algorithm and application to a long-term polarimetric dataset. J. Appl. Meteor. Climatol., 52, 2162-2186, https://doi.org/10.1175 /JAMC-D-12-0275.1.

Drushka, K., W. E. Asher, B. Ward, and K. Walesby, 2016: Understanding the formation and evolution of rain-formed fresh lenses at the ocean surface. $J$. 
Geophys. Res. Oceans, 123, 2673-2689, https://doi .org/10.1002/2015JC011527.

Herzegh, P. H., and A. R. Jameson, 1992: Observing precipitation through dual-polarization radar measurements. Bull. Amer. Meteor. Soc., 73, 1365-1374, https:// doi.org/10.1175/1520-0477(1992)073<1365:OPTDPR $>2.0 . \mathrm{CO} ; 2$.

Houze, R. A., Jr., 1977: Structure and dynamics of a tropical squall line system. Mon. Wea. Rev., 105, 1540-1567, https://doi.org/10.1175/1520 -0493(1977)105<1540:SADOAT>2.0.CO;2.

— , and C.-P. Cheng, 1977: Radar characteristics of tropical convection observed during GATE: Mean properties and trends over the summer season. Mon. Wea. Rev., 105, 964-980, https://doi .org/10.1175/1520-0493(1977)105<0964:RCOTCO $>2.0 . \mathrm{CO} ; 2$.

Johnson, R. H., S. L. Aves, and P. E. Ciesielski, 2005: Organization of oceanic convection during the onset of the 1998 East Asian summer monsoon. Mon. Wea. Rev., 133, 131-148, https://doi.org/10.1175 /MWR-2843.1.

Kennedy, P. C., and S. A. Rutledge, 2011: S-band dualpolarization radar observations of winter storms. J. Appl. Meteor. Climatol., 50, 844-858, https://doi .org/10.1175/2010JAMC2558.1.

Kumjian, M. R., 2018: Weather Radars. Remote Sensing of Clouds and Precipitation. C. Andronache, Ed., Springer, 15-64.

— and A. V. Ryzhkov, 2012: The impact of size sorting on the polarimetric radar variables. J. Atmos. Sci., 69, 2042-2060, https://doi.org/10.1175/JAS-D-11-0125.1.

— - and O. P. Prat, 2014: The impact of raindrop collisional processes on the polarimetric radar variables. J. Atmos. Sci., 71, 3052-3067, https://doi.org/10.1175 /JAS-D-13-0357.1.

- , and K. A. Lombardo, 2017: Insights into the evolving microphysical and kinematic structure of northeastern U.S. winter storms from dual-polarization Doppler radar. Mon. Wea. Rev., 145, 1033-1061, https://doi.org/10.1175/MWR-D-15-0451.1.

— , S. A. Rutledge, R. M. Rasmussen, P. C. Kennedy, and M. Dixon, 2014: High-resolution polarimetric radar observations of snow-generating cells. $J$. Appl. Meteor. Climatol., 53, 1636-1658, https://doi .org/10.1175/JAMC-D-13-0312.1.

Morrison, H., 2016: Impacts of updraft size and dimensionality on the perturbation pressure and vertical velocity in cumulus convection. Part I: Simple, generalized analytic solutions. J. Atmos. Sci., 73, 1441-1454, https://doi.org/10.1175/JAS-D-15-0040.1.

Petersen, W. A., S. A. Rutledge, and R. E. Orville, 1996: Cloud-to-ground lightning observations from TOGA
COARE: Selected results and lightning location algorithms. Mon. Wea. Rev., 124, 602-620, https:// doi.org/10.1175/1520-0493(1996)124<0602:CTGLOF $>2.0 . \mathrm{CO} ; 2$.

- R. C. Cifelli, S. A. Rutledge, B. S. Ferrier, and B. F. Smull, 1999: Shipborne dual-Doppler operations during TOGA COARE: Integrated observations of storm kinematics and electrification. Bull. Amer. Meteor. Soc., 80, 81-97, https://doi.org/10.1175/1520 -0477(1999)080<0081:SDDODT>2.0.CO;2.

,-- D. J. Boccippio, S. A. Rutledge, and C. Fairall, 2003: Convection and easterly wave structures observed in the eastern Pacific warm pool during EPIC-2001. J. Atmos. Sci., 60, 1754-1773, https://doi .org/10.1175/1520-0469(2003)060<1754:CAEWSO $>2.0 . \mathrm{CO} ; 2$.

Powell, S. W., R. A. Houze Jr., and S. R. Brodzik, 2016: Rainfall-type categorization of radar echoes using polar coordinate data. J. Atmos. Oceanic Technol., 33, 523-538, https://doi.org/10.1175 /JTECH-D-15-0135.1.

Rauber, R. M., and S. W. Nesbitt, 2018: Radar Meteorology: A First Course. Wiley Blackwell, $461 \mathrm{pp}$. Rickenbach, T. M., and S. A. Rutledge, 1998: Convection in TOGA COARE: Horizontal scale, morphology and rainfall production. J. Atmos. Sci., 55, 2715-2729, https://doi.org/10.1175/1520-0469(1998)055<2715: CITCHS $>2.0 . C O ; 2$.

Rutledge, S. A., V. Chandrasekar, B. Fuchs, J. George, F. Junyent, P. Kennedy, and B. Dolan, 2019: Deployment of the SEA-POL C-band Polarimetric Radar to SPURS-2. Oceanogr., 32(2), 50-57, https://doi .org/10.5670/oceanog.2019.212.

Ryzhkov, A. V., S. E. Giangrande, V. M. Melnikov, and T. J. Schuur, 2005a: Calibration issues of dualpolarization radar measurements. J. Atmos. Oceanic Technol., 22, 1138-1155, https://doi.org/10.1175/ JTECH1772.1.

- - - and T. J. Schuur, 2005b: Rainfall estimation with a polarimetric prototype of WSR88D. J. Appl. Meteor., 44, 502-515, https://doi .org/10.1175/JAM2213.1.

-, T. J. Schuur, D. W. Burgess, P. L. Heinselman, S. E. Giangrande, and D. S. Zrnic, 2005c: The Joint Polarization Experiment. Bull. Amer. Meteor. Soc., 86, 809-823, https://doi.org/10.1175/BAMS-86-6 $-809$.

-, M. Diederich, P. Zhang, and C. Simmer, 2014: Potential utilization of specific attenuation for rainfall estimation, mitigation of partial beam blockage, and radar networking. J. Atmos. Oceanic Technol., 31, 599-619, https://doi.org/10.1175 /JTECH-D-13-00038.1. 
Steiner, M., R. A. Houze Jr., and S. E. Yuter, 1995: Climatological characterization of three-dimensional storm structure from operational radar and rain gauge data. J. Appl. Meteor., 34, 1978-2007, https:// doi.org/10.1175/1520-0450(1995)034<1978:CCOTDS $>2.0 . \mathrm{CO} ; 2$.

Thompson, E. J., S. A. Rutledge, B. Dolan, V. Chandrasekar, and B. L. Cheong, 2014: A dualpolarization hydrometeor classification algorithm for winter precipitation. J. Atmos. Oceanic Technol., 31, 1457-1481, https://doi.org/10.1175/JTECH -D-13-00119.1.

,,--- , and M. Thurai, 2015: Drop size distributions and radar observations of convective and stratiform rain over the equatorial Indian and $\mathrm{W}$. Pacific oceans. J. Atmos. Sci., 72, 4091-4125, https:// doi.org/10.1175/JAS-D-14-0206.1.

,,,---- , and V. Chandrasekar, 2018: Dualpolarization radar rainfall estimation over tropical oceans. J. Appl. Meteor. Climatol., 57, 755-775, https://doi.org/10.1175/JAMC-D-17-0160.1.

Thurai, M., P. T. May, and A. Protat, 2014: Shipborne polarimetric radar: Impact of ship movement on polarimetric variables at $\mathrm{C}$ band. J. Atmos. Oceanic Technol., 31, 1557-1563, https://doi.org/10.1175 /JTECH-D-13-00242.1.

Wang, Y., and V. Chandrasekar, 2009: Algorithm for estimation of the specific differential phase. $J$. Atmos. Oceanic Technol., 26, 2565-2578, https://doi .org/10.1175/2009JTECHA1358.1.

Webster, P. J., and R. A. Houze Jr., 1991: The Equatorial Mesoscale Experiment (EMEX): An overview. Bull. Amer. Meteor. Soc., 72, 1481-1505, https://doi .org/10.1175/1520-0477(1991)072<1481:TEMEAO $>2.0 . \mathrm{CO} ; 2$.

- , and Coauthors, 2002: The JASMIME pilot study. Bull. Amer. Meteor. Soc., 83, 1603-1630, https://doi .org/10.1175/BAMS-83-11-1603.
Wei, D., A. M. Blyth, and D. J. Raymond, 1998: Buoyancy of convective clouds in TOGA COARE. J. Atmos. Sci., 55, 3381-3391, https://doi.org/10.1175/1520 -0469(1998)055<3381:BOCCIT>2.0.CO;2.

Wood, R., and Coauthors, 2011: The VAMOS OceanCloud-Atmosphere-Land Study Regional Experiment (VOCALS-Rex): Goals, platforms and field operations. Atmos. Chem. Phys., 11, 627-654, https://doi .org/10.5194/acp-11-627-2011.

$\mathrm{Xu}, \mathrm{W}$., and S. A. Rutledge, 2014: Convective characteristics of the Madden-Julian oscillation over the central Indian Ocean observed by shipborne radar during DYNAMO. J. Atmos. Sci., 71, 2859-2877, https://doi .org/10.1175/JAS-D-13-0372.1.

$\longrightarrow$, and — 2015: Morphology, intensity, and rainfall production of MJO convection: Observations from DYNAMO shipborne radar and TRMM. J. Atmos. Sci., 72, 623-640, https://doi.org/10.1175 /JAS-D-14-0130.1.

Yuter, S. E., and R. A. Houze Jr., 2000: The 1997 Pan American Climate Studies Tropical Eastern Pacific Process Study: Part I: ITCZ region. Bull. Amer. Meteor. Soc., 81, 451-481, https://doi.org/10.1175/1520 -0477(2000)081<0451:TPACST>2.3.CO;2.

,-- , E. A. Smith, T. T. Wilheit, and E. J. Zipser, 2005: Physical characterization of tropical convection observed in KWAJEX. J. Appl. Meteor., 44, 385-415, https://doi.org/10.1175/JAM2206.1.

Zipser, E. J., 1977: Mesoscale and convective-scale downdrafts as distinct components of squall like structure. Mon. Wea. Rev., 105, 1568-1589, https://doi .org/10.1175/1520-0493(1977)105<1568:MACDAD $>2.0 . \mathrm{CO} ; 2$.

— reflectivity of convective cells: A strong indicator of storm intensity and lightning probability. Mon. Wea. Rev., 122, 1751-1759, https://doi.org/10.1175/1520 -0493(1994)122<1751:TVPORR>2.0.CO;2. 
